\title{
CPAP as treatment of sleep apnea after stroke
}

\section{A meta-analysis of randomized trials}

Anne-Kathrin Brill, MD,* Thomas Horvath, MD,* Andrea Seiler, MD, Millene Camilo, PhD, Alan G. Haynes, PhD, Sebastian R. Ott, MD, Matthias Egger, MD, and Claudio L. Bassetti, MD

Neurology ${ }^{\circledR}$ 2018;90:e1222-e1230. doi:10.1212/WNL.0000000000005262

\author{
Correspondence \\ Prof. Bassetti \\ claudio.bassetti@insel.ch
}

\section{Abstract \\ Objective}

To perform a systematic review and meta-analysis of randomized controlled trials (RCTs) examining the effectiveness of continuous positive airway pressure (CPAP) in stroke patients with sleep disordered breathing (SDB).

\section{Methods}

In a systematic literature search of electronic databases (MEDLINE, Embase, and the Cochrane Library) from 1980 to November 2016, we identified RCTs that assessed CPAP compared to standard care or sham CPAP in adult patients with stroke or TIA with SDB. Mean CPAP use, odds ratios (ORs), and standardized mean differences (SMDs) were calculated. The prespecified outcomes were adherence to CPAP, neurologic improvement, adverse events, new vascular events, and death.

\section{Results}

Ten RCTs (564 participants) with CPAP as intervention were included. Two studies compared CPAP with sham CPAP; 8 compared CPAP with usual care. Mean CPAP use across the trials was 4.53 hours per night ( $95 \%$ confidence interval [CI] 3.97-5.08). The OR of dropping out with CPAP was 1.83 (95\% CI 1.05-3.21, $p=0.033$ ). The combined analysis of the neurofunctional scales (NIH Stroke Scale and Canadian Neurological Scale) showed an overall neurofunctional improvement with CPAP (SMD 0.5406, 95\% CI 0.0263-1.0548) but with a considerable heterogeneity $\left(I^{2}=78.9 \%, p=0.0394\right)$ across the studies. Long-term survival was improved with CPAP in 1 trial.

\section{Conclusion}

CPAP use after stroke is acceptable once the treatment is tolerated. The data indicate that CPAP might be beneficial for neurologic recovery, which justifies larger RCTs.

*These authors contributed equally to this work.

From the Department of Pulmonary Medicine (A.-K.B., S.R.O.), Department of Neurology (T.H., A.S., M.C., C.L.B.), and Sleep Wake Epilepsy Center (A.-K.B., T.H., A.S., M.C., S.R.O., C.L.B.), Inselspital, University Hospital Bern, University of Bern, Switzerland; Neurology Division (M.C.), Department of Neuroscience and Behavioral Sciences, University of São Paulo, Brazil; and CTU Bern (A.G.H.) and Institute of Social and Preventive Medicine (A.G.H., M.E.), University of Bern, Switzerland.

Go to Neurology.org/N for full disclosures. Funding information and disclosures deemed relevant by the authors, if any, are provided at the end of the article. 


\section{Glossary}

AHI = apnea-hypopnea index $\mathbf{C I}=$ confidence interval; $\mathbf{C N S}=$ Canadian Neurological Scale; $\mathbf{C P A P}=$ continuous positive airway pressure; NIHSS = NIH Stroke Scale; OSA = obstructive sleep apnea; PRISMA = Preferred Reporting Items for Systematic Reviews and Meta-Analyses; RCT = randomized controlled trial; SDB = sleep disordered breathing.

Sleep disordered breathing (SDB) with an apnea-hypopnea in$\operatorname{dex}(\mathrm{AHI})>15 / \mathrm{h}$ is present in $\approx 26 \%$ of the general population and a common comorbidity in stroke survivors. ${ }^{1-3}$ The reported prevalence after stroke varies between $50 \%$ and $70 \%$, depending on the chosen cutoff for the $\mathrm{AHI}$ and time lag from stroke, but it is consistently higher in acute stroke patients than in the general population. ${ }^{4,5} \mathrm{SDB}$ can improve after the acute stroke phase, but up to $60 \%$ of the patients still show an $\mathrm{AHI}>10 / \mathrm{h}$ and $30 \%$ show an $\mathrm{AHI}>30 / \mathrm{h} \approx 3$ months after the stroke or TIA. ${ }^{1,2,4}$ Most of the stroke patients have obstructive sleep apnea (OSA), which has been identified as an independent risk factor for stroke and is associated with a higher mortality. ${ }^{6-9}$

Treatment of OSA with continuous positive airway pressure (CPAP) leads to improvements in sleepiness and cognitive performance in the general population, but the data on the prevention of cardiovascular or cerebrovascular disease ${ }^{10-13}$ and its effects on neurologic recovery after stroke ${ }^{14}$ are still conflicting. Identifying and treating OSA in stroke survivors was added to the American Heart Association/American Stroke Association stroke guidelines in 2014 with a Class IIb recommendation and Level of Evidence $\mathrm{B} .{ }^{15}$ However, the timing of diagnostic investigations and treatment initiation has not been specified, and unlike other independent risk factors for stroke, e.g., arterial hypertension or dyslipidemia, which are usually identified and treated in stroke patients within the first days after hospital admission, the treatment of SDB is still often neglected. ${ }^{16}$ Concerns include the feasibility and effectiveness of CPAP in the acute setting, which might partially explain the large number of undiagnosed and untreated patients and delays between admission for stroke and start of OSA treatment. ${ }^{4,17}$

In addition to nonrandomized observational studies with matched control groups, more randomized controlled trials (RCTs) using CPAP have been published recently in stroke cohorts. Thus, the objective of the present study was to systematically review and analyze the literature on treatment of SDB in adult patients after TIA or stroke with regard to acceptance of CPAP and its effectiveness to modify clinical outcome parameters.

\section{Methods}

This systematic review and meta-analysis is reported according to the PRISMA (Preferred Reporting Items for Systematic Reviews and Meta-Analyses) guidelines. ${ }^{18}$

\section{Search strategy}

We performed a systematic search of MEDLINE, Embase, and the Cochrane Library between January 1980 and
November 2016 to identify RCTs comparing CPAP with sham CPAP or usual care to treat SDB in adult patients after a TIA or stroke. The full list of search terms is included in tables e-1 through e-3 (links.lww.com/WNL/A320). To identify additional trials, we examined reference lists of the identified articles, relevant reviews in the field, and clinical trial registries.

\section{Study selection}

Study selection was performed in duplicate by 2 independent authors (A.-K.B.,T.H.). Disagreement was resolved by discussion with a third author (A.S.). The titles and abstracts of identified publications were screened, and potentially relevant articles were retrieved for a full-text review. A full list of inclusion and exclusion criteria is given in table e-4 (links.lww. com/WNL/A320). In short, inclusion was restricted to fulltext RCTs comparing CPAP with sham CPAP or usual care to treat SDB in adult patients after a stroke or TIA. There were no language restrictions. We excluded duplicate publications, all study designs other than RCTs, abstracts, conference communications, and other interventions to treat SDB.

\section{Data extraction}

The prespecified outcomes for the meta-analysis were nightly use (adherence), reduction of AHI compared to baseline; dropouts; improvement of the NIH Stroke Scale (NIHSS), Canadian Neurological Scale (CNS), or other neurofunctional and cognitive parameters ${ }^{19}$; adverse events related to the intervention; new vascular events; and mortality (table e-4, links.lww.com/WNL/A320). If multiple reports were available for 1 trial, we used information of all reports for data extraction but extracted outcome data only once on the basis of completeness and follow-up.

All data were extracted independently and in duplicate (A.-K.B., T.H.) for each included RCT with a standardized prespecified data collection form. If multiple follow-up time points were present, the longest follow-up was considered. Studies were divided into early treatment, defined as treatment onset within 7 days after a cerebrovascular event, and delayed treatment, starting $>7$ days after TIA or stroke. We contacted the authors of all RCTs to obtain additional individual patient data on neurologic outcomes.

\section{Assessment of risk of bias}

The quality of each included RCT was assessed with the Cochrane risk of bias tool, which covers 6 domains of bias: selection bias, performance bias, detection bias, attrition bias, reporting bias, and other bias. ${ }^{20}$ For each RCT, 2 reviewers (A.-K.B., T.H.) independently assigned a score of high, low, or 
unclear quality for each domain. Disagreement was resolved by discussion with a third author (M.C.).

\section{Statistical analysis}

Mean CPAP use per night (compliance), odds ratios of dropping out of the trial, and standardized mean differences (expressed as the Hedge g) in NIHSS and CNS scores were combined in DerSimonian-Laird random-effects metaanalysis. Heterogeneity was assessed with $I^{2}$ statistics, with $I^{2}$ values of $>50 \%$ considered as substantial heterogeneity and $I^{2}>75 \%$ as considerable heterogeneity. ${ }^{21} \mathrm{We}$ intended to assess publication bias using funnel plot techniques, the Begg rank test, and the Egger regression test, as appropriate. We used the meta package in $\mathrm{R}$ (version 3.3.2; R Foundation for Statistical Computing, Vienna, Austria) for all analyses. ${ }^{22,23}$ Results are presented as estimates with 95\% confidence intervals (CIs).

\section{Results}

\section{Search results}

From 2,880 publications that were retrieved by the literature search, we identified 27 studies (30 full-text publications) with interventions to treat SDB after TIA or stroke (figure 1 and table e-5, links.lww.com/WNL/A320). Ten studies were RCTs using CPAP to treat OSA to improve post-TIA or poststroke outcomes in adults and were included in the metaanalysis (table 1).

\section{Study characteristics}

The included RCTs that randomized a total of 564 participants with TIA or clinically or imaging-confirmed stroke. Four RCTs provided information on stroke subtypes according to the etiology or the vascular territory ${ }^{24-27}$; 1 RCT differentiated between hemorrhagic and ischemic stroke. ${ }^{28}$ In 7 RCTs, prediagnosed or already treated SDB was an exclusion criterion. The other 3 studies did not provide information on preexisting SDB. ${ }^{25,29,30}$ Mean baseline AHI ranged from $11 / \mathrm{h}$ to $38.5 / \mathrm{h}$ and depended on the studyspecific inclusion criteria (table e-5, links.lww.com/WNL/ A320). ${ }^{26,31}$ Three studies did not assess AHI at inclusion because of immediate initiation of CPAP and a delayed performance of the diagnostic polysomnography. ${ }^{25,32,33}$ Studies were performed in acute care hospitals or in rehabilitation units with study durations and follow-ups varying between 8 days and 5 years. The sample size varied between 30 and 140 participants.

In 5 trials, treatment was started early within 7 days after stroke. The other 5 studies initiated treatment 10 to 28 days after the cerebrovascular event (table e-5, links.lww.com/ WNL/A320). Details of the individual study characteristics are provided in table 1 and table e-5.

\section{Assessment of risk of bias}

The individual risk of bias in the 10 RCTs was mixed with an overall high risk of bias for blinding of participants in the open-label studies and a lower risk in the more recent trials (table e-6, links.lww.com/WNL/A320). ${ }^{24,28,31}$ Publication bias was not assessed because there were inadequate numbers of included trials to properly assess a funnel plot or more advanced regression-based assessments.

\section{Reduction of AHI, dropouts, and compliance}

Information on the reduction of AHI with CPAP was reported in 3 studies and reached a mean AHI of $<10 / \mathrm{h}^{24-26}$

Dropouts and adherence to CPAP were evaluated in all trials. Dropout rates ranged from $0 \%$ to $46 \%$, with more dropouts in the CPAP groups than for sham CPAP or usual care. There were more dropouts in the trials starting CPAP early. The combined odds ratio of dropping out was 1.83 (95\% CI $1.05-3.21, p=0.033)$ with no between-study heterogeneity $\left(I^{2}=0 \%\right)$ (figure 2$)$.

Seven RCTs reported a mean CPAP use of $\geq 4$ hours a night, and 2 had a mean CPAP use $<4$ hours a night, resulting in a combined mean CPAP use of 4.53 hours a night (95\% CI 3.97-5.08), but with considerable heterogeneity $\left(I^{2}=87.2 \%, p<0.0001\right)$ across the studies (figure 3 and table 1). CPAP use and heterogeneity were similar in the subgroup analysis $\left(p=0.0631\right.$, early CPAP $I^{2}$ $=84.0 \%$, delayed CPAP $\left.I^{2}=84.2 \%\right)$. One study with a reported low adherence could not be included in the meta-analysis because of insufficient data in the publication and no reply from the authors. ${ }^{29}$

Factors associated with poor adherence were neurologic impairment, mask discomfort, depressive symptoms, or subjective sleep disturbance. ${ }^{29,30}$ None of the RCTs assessed a potential association between excessive daytime sleepiness or preexisting SDB and subsequent CPAP use.

\section{Adverse events}

Four RCTs reported details on adverse events. ${ }^{26,27,32,33}$ Serious adverse events not related to the study intervention were mentioned in the 2 studies without differences between CPAP and controls (patients with TIA: CPAP, 7 events in 45 participants [15.6\%], and controls, 4 events in 25 participants [16\%]; stroke patients: CPAP, 2 events in 31 patients [6.5\%], and controls, 5 events in 24 participants [20.8\%]). ${ }^{32,33}$ There were no serious adverse events related to CPAP. Nonserious adverse events were more frequent in the CPAP groups and were related mainly to the mask (e.g., facial marks or dry noses). ${ }^{32,33}$

\section{Neurofunctional outcomes}

Neurofunctional changes were assessed in 6 RCTs with the NIHSS and CNS at baseline and follow-up. In 2 studies, the NIHSS score was available only for baseline or follow-up ${ }^{28,31}$; 1 study assessed patients with TIA only ${ }^{32}$; and 1 study did not provide NIHSS or CNS scores. ${ }^{30}$ Independency scales were the Barthel Index, modified Rankin Scale, Functional 


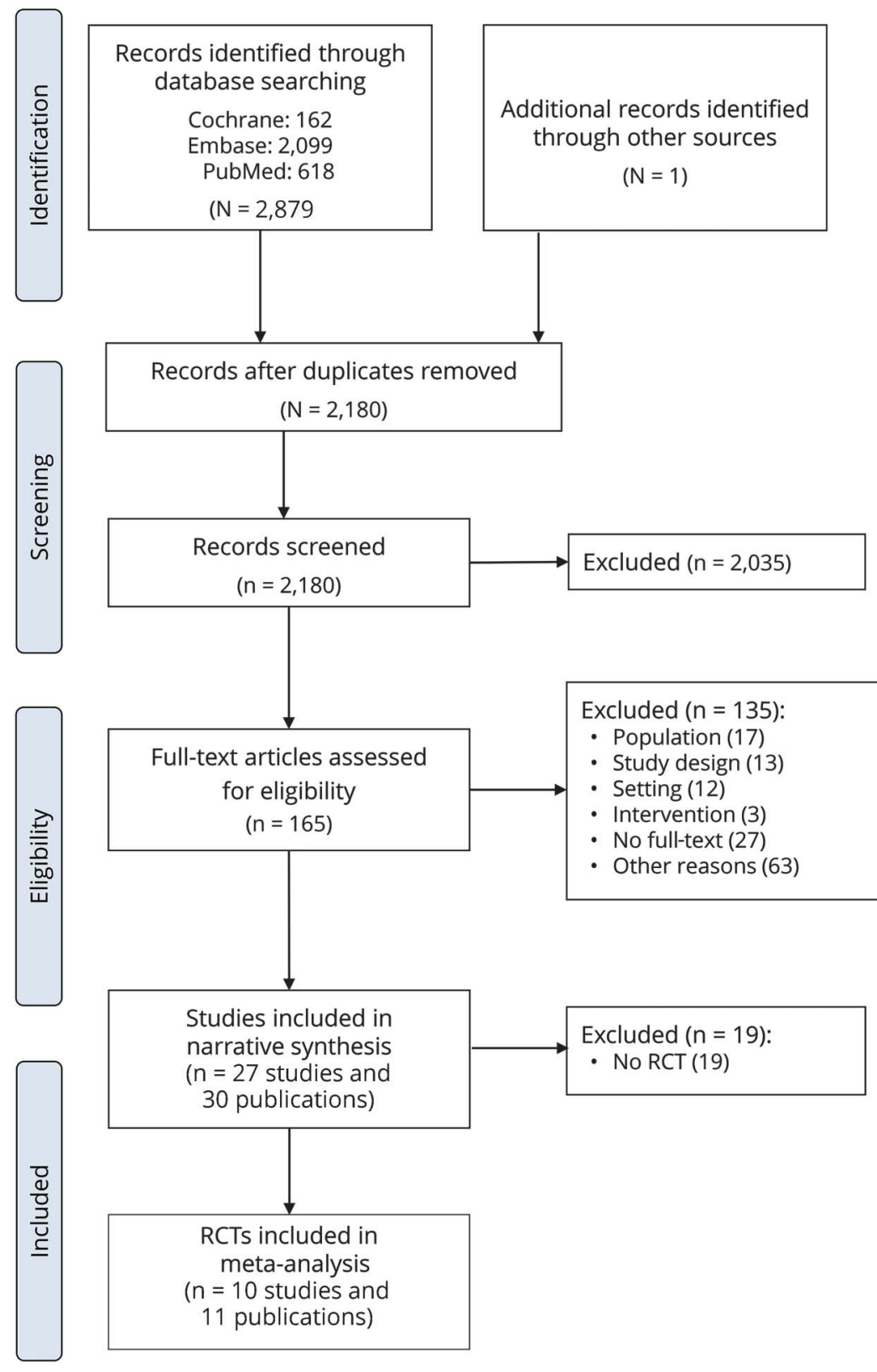

$\mathrm{RCT}=$ randomized controlled trial.

Independence Measure score, or Utrecht Scale for Evaluation of Rehabilitation.

Additional individual patient data on the NIHSS or CNS and independency scales were provided by 5 authors. $^{24-27,33}$ In the combined analysis of the neurofunctional scales (NIHSS and CNS) of these 5 studies and 1 study with original data from the publication, ${ }^{29}$ the standardized mean difference showed overall a neurofunctional improvement with CPAP with a standardized mean difference of 0.5406 (95\% CI 0.0263-1.0548). The heterogeneity of the studies was high with $I^{2}=78.9 \%(p=$ $0.0394)$ and a $z$ test of $2.06(p=0.0394)$ (figure 4$)$, and subgroup analyses of early and delayed CPAP trials showed nonsignificant changes. Independency scales remained unchanged within the individual studies. An individual correction of the neurofunctional or independency scores for adherence was not realizable. However, a greater improvement in NIHSS score was mentioned in patients with a better adherence to CPAP in 2 publications. ${ }^{25,33}$ The results were not affected by the stroke subtypes.

\section{Neurocognitive functions, depression, and sleepiness}

Because of different scales and heterogeneity of the reported data, a meta-analysis of these outcomes was not possible. 
Table 1 Characteristics of the included CPAP RCTs

\begin{tabular}{|c|c|c|c|c|c|c|c|c|c|}
\hline Study & Comparator & Participants, $n$ & CPAP group, $n$ & Follow-up & Age, $y$ & Female, $\%$ & BMI, $\mathrm{kg} / \mathrm{m}^{2}$ & CPAP use, h/night & Dropouts, n (\%) \\
\hline \multicolumn{10}{|l|}{ Early CPAP treatment } \\
\hline \multirow[t]{2}{*}{ Bravata et al, ${ }^{32} 2010$} & UC & 70 & 45 & $90 \mathrm{~d}$ & CPAP $47-88$ & CPAP 48.9 & CPAP $28.6 \pm 4.1$ & $5.6(5.15-6.06)^{a}$ & CPAP $9(20)$ \\
\hline & & & & & Control $45-88$ & Control 52 & Control $27.8 \pm 6.5$ & & Control 5 (20) \\
\hline \multirow[t]{2}{*}{ Bravata et al, ${ }^{33} 2011$} & UC & 55 & 31 & $30 \mathrm{~d}$ & CPAP 52-88 & CPAP 32.3 & CPAP $26.8 \pm 4.3$ & $5.10(4.49-5.71)^{a}$ & CPAP 9 (29) \\
\hline & & & & & Control 50-94 & Control 33.3 & Control $29.4 \pm 7.2$ & & Control 3 (13) \\
\hline \multirow[t]{2}{*}{ Minnerup et al $_{1}^{25} 2012$} & UC & 50 & 25 & 8 nights & CPAP $68.6 \pm 10$ & CPAP 64 & CPAP $27.8 \pm 2.5$ & $4.2(3.79-5.61)^{\mathrm{a}}$ & None \\
\hline & & & & & Control $63.4 \pm 10.5$ & Control 60 & Control $26.7 \pm 3.1$ & & \\
\hline \multirow[t]{2}{*}{ Brown et al, ${ }^{31} 2013$} & Sham & 32 & 15 & $3 \mathrm{mo}$ & CPAP 61 (46-76) & CPAP 67 & CPAP 28 (23-31) & CPAP $4.2(2.6-5.5)$ & CPAP 7 (47) \\
\hline & & & & & Control 74 (55-81) & Control 24 & Control $29(28-32)$ & Sham $3.5(1.8-4.1)$ & Sham 6 (35) \\
\hline \multirow{2}{*}{ Parra et al, ${ }^{27,34} 2011,2015$} & UC & 140 & 71 & $24 \mathrm{mo}$ & CPAP $63.7 \pm 9.1$ & CPAP 28.1 & CPAP $30.2 \pm 4.6$ & $5.3(4.99-5.61)^{\mathrm{a}}$ & None \\
\hline & & & & $68 \mathrm{mo}$ & Control $65.5 \pm 9.1$ & Control 30.4 & Control $28.8 \pm 4$ & $1 \mathrm{wk}$ after stroke & \\
\hline \multicolumn{10}{|l|}{ Delayed CPAP treatment } \\
\hline \multirow[t]{2}{*}{ Sandberg et al, ${ }^{30} 2001$} & UC & 63 & 33 & $28 d$ & CPAP $78.1 \pm 6.4$ & CPAP 54.8 & CPAP $24.5 \pm 4.1$ & $4.1(3.21-4.99)^{a}$ & CPAP 2 (6) \\
\hline & & & & & Control $6.8 \pm 7.9$ & Control 53.6 & Control $24.8 \pm 4.8$ & & Control 2 (7) \\
\hline \multirow[t]{2}{*}{ Hsu et al, ${ }^{29} 2006$} & UC & 30 & 15 & $6 \mathrm{mo}$ & CPAP 74 (73-81) & CPAP 26.7 & CPAP $26.8(21-28.5)$ & Mean 1.4 & CPAP $3(20)$ \\
\hline & & & & $8 \mathrm{wk}$ & Control $73(65-77)$ & Control 40 & Control 25.1 (22.1-33.1) & Median 0.16 over $8 \mathrm{wk}$ & Control $0(0)$ \\
\hline \multirow[t]{2}{*}{ Ryan et al, ${ }^{26} 2011$} & UC & 48 & 25 & $4 \mathrm{wk}$ & CPAP $2.8 \pm 12.8$ & CPAP 27.3 & CPAP $28.8 \pm 5.3$ & $4.96(4.32-5.60)^{a}$ & CPAP 3 (12) \\
\hline & & & & & Control $60.7 \pm 10.3$ & Control 13.6 & Control $27.3 \pm 5.8$ & & Control 1 (4) \\
\hline \multirow[t]{2}{*}{ Khot et al, ${ }^{28} 2016$} & Sham & 40 & 20 & $28 d$ & CPAP $55.9 \pm 12.1$ & CPAP 50 & CPAP $31 \pm 5.7$ & CPAP $3.9 \pm 2.7$ & CPAP 7 (35) \\
\hline & & & & & Control $56.5 \pm 12.1$ & Control 40 & Control $28.5 \pm 4$ & Sham $3.6 \pm 1.8$ & Sham $3(15)$ \\
\hline \multirow[t]{2}{*}{ Aaronson et al, ${ }^{24} 2016$} & UC & 36 & 20 & $2 \mathrm{mo}$ & CPAP $61.1 \pm 8.2$ & CPAP 40 & CPAP $28.1 \pm 6.4$ & $2.50(1.59-3.41)^{a}$ & CPAP 6 (30) \\
\hline & & & & $4 \mathrm{wk}$ & Control $56.7 \pm 8.8$ & Control 37.5 & Control $25.8 \pm 4.7$ & & Control 4 (25) \\
\hline
\end{tabular}

Abbreviations: $\mathrm{AHI}=$ apnea-hypopnea index; $\mathrm{BMI}=$ body mass index; $\mathrm{CPAP}=$ continuous positive airway pressure; $\mathrm{RCT}=$ randomized controlled trial; $\mathrm{UC}=$ usual care . Data are presented as ranges, mean $\pm \mathrm{SD}$, or median (interquartile range) unless otherwise indicated. 
Figure 2 Forest plot representing the probability to drop out (random-effects model)

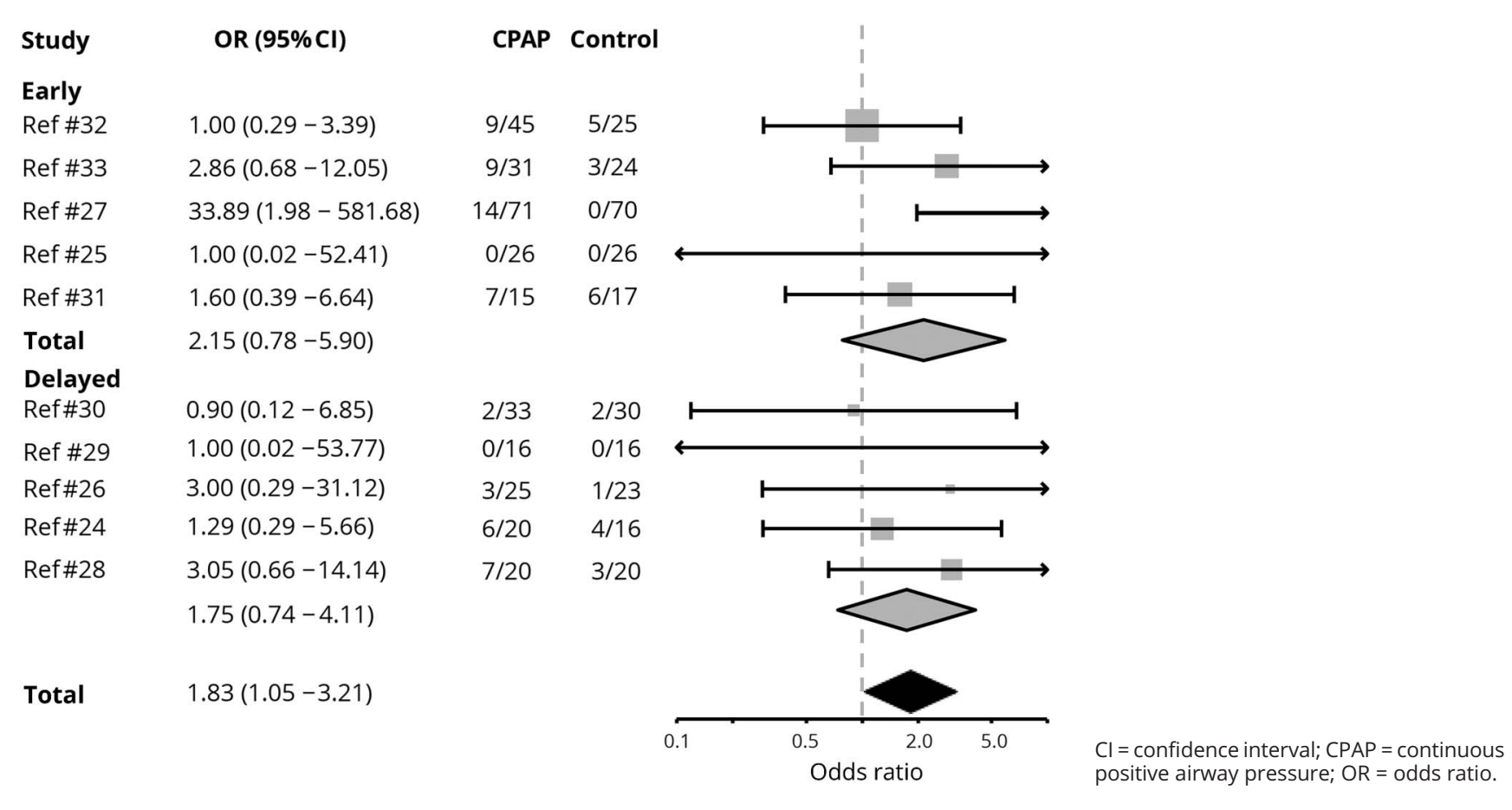

There was an improvement in neurocognitive tests in the intention-to-treat analyses in the CPAP group in the 2 most recent RCTs, ${ }^{24,28}$ while there were no significant differences in standard cognitive screening tests in others. ${ }^{29,30}$ Three trials assessed depressive symptoms, ${ }^{26,30,31}$ and 2 found an improvement in favor of the CPAP treatment. ${ }^{26,30}$ Findings on sleepiness were inconsistent: 2 RCTs, one of them starting CPAP in the acute setting, did not find a difference, ${ }^{33,34}$ whereas the third trial found significant differences in favor of CPAP. $^{26}$

Figure 3 Forest plot representing the adherence to CPAP treatment in hours per night (random-effects model)

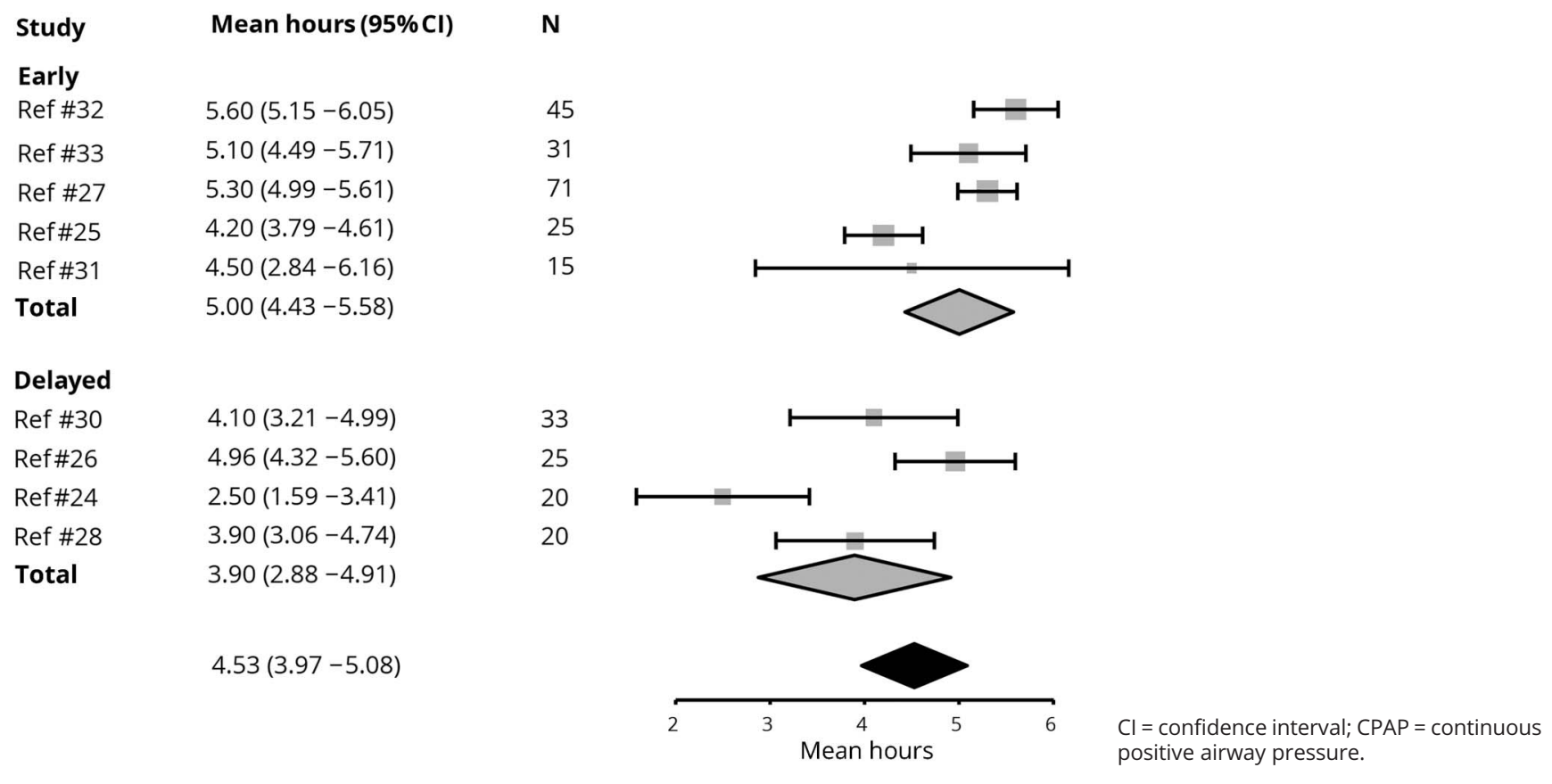




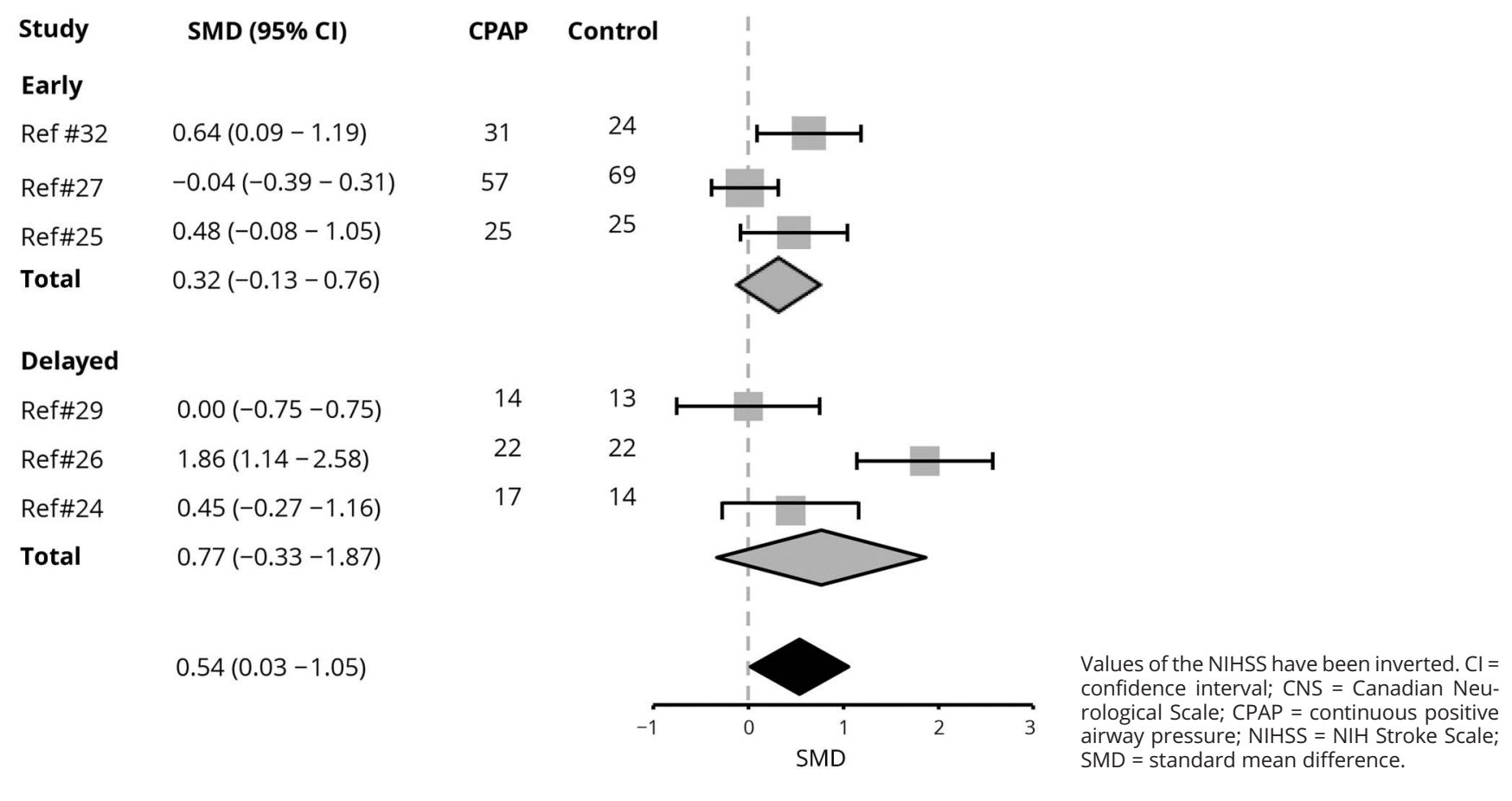

\section{New vascular events and mortality}

Two RCTs with early CPAP found no significant differences in the few combined vascular events (recurrent TIA, stroke, myocardial infarction, hospitalization for congestive heart failure, death) that were recorded within the studies, but the trials were neither long enough nor sufficiently powered for this outcome. ${ }^{32,33}$ An improvement in cardiovascular survival compared to usual care was found in a long-term follow-up over 5 years. ${ }^{34}$ In this RCT, CPAP compared to usual care was associated with a longer time to the next cardiovascular event ( 14.9 vs 7.9 months), but there was no significant difference in the overall cardiovascular event-free survival, and the generalizability of these findings is limited by a small sample size. $^{27,34}$

\section{Discussion}

This meta-analysis shows that adherence to CPAP treatment, once tolerated, is acceptable in stroke survivors with SDB in the acute and more chronic setting. The overall adherence of study participants of 4.5 hours a night seems remarkable because compliance to CPAP is already a difficult issue in the general SDB population and is even more challenging in neurologically impaired stroke survivors and the particularly difficult environmental circumstances of stroke units. However, this high adherence rate has to be interpreted with caution and needs to be balanced against the fact that most of the RCTs were designed as feasibility studies with short and variable durations of the intervention and heterogeneous follow-up intervals. The difficult recruitment of stroke patients and their high dropout rates in clinical trials were also seen in the trials included in this meta-analysis, even in the newer RCTs. ${ }^{35}$ Early dropouts were not considered for the analysis in most RCTs, which may also bias the reported adherence rates and lead to an overestimation. In addition, the number of rather mildly affected patients might have been higher in the RCTs than it is to be expected in routine practice.

CPAP treatment was judged as safe across the trials, and no serious adverse events related to the intervention were reported. Similar to CPAP trials in the general population, nonserious adverse events, related to the mask, were more frequent in the CPAP groups and would probably be acceptable if a beneficial treatment effect could be demonstrated.

SDB after ischemic stroke is believed to contribute to neural damage and a worse stroke outcome by affecting the perfusion and oxygenation of the penumbra. ${ }^{7,11,36}$ In theory, the early application of CPAP may therefore contribute to a longer survival of the penumbra and result in clinically and radiologically measurable neurologic improvements. Short-term neuroimaging effects have not been investigated sufficiently in the available trials, but in terms of the neurofunctional outcomes, a recent review and meta-analysis on noninvasive ventilator correction in patients with acute ischemic stroke postulated a positive association of noninvasive ventilator correction and short-term neurologic improvement. ${ }^{37}$ This meta-analysis included only 2 small RCTs and 1 observational study with a matched control group in the analysis of the 
neurologic outcome, which explains the low heterogeneity but also weakens the significance of their findings. Our analysis included more studies and additional individual patient data, and the subgroup analysis of the included early treatment initiation trials showed no significant difference between $\mathrm{CPAP}$ and the comparator. This indicates the need for a larger sample size to evaluate whether CPAP is really beneficial for early neurologic recovery.

A delayed start of CPAP might not be able to influence the penumbra anymore, but because SDB contributes independently to cognitive dysfunction, sleepiness, and depression, a positive treatment effect on these components could lead to a better participation in the rehabilitation program and support the recovery from stroke. ${ }^{36}$ Despite the statistically significant result across all 6 included trials favoring $\mathrm{CPAP}$, the subgroup analysis of neurofunctional change of the delayed starting RCTs also remained nonsignificant.

CPAP adherence led to better neurologic outcomes in 2 RCTs, which is in line with adherence analyses performed for the effect of CPAP on blood pressure that showed treatment results in favor of CPAP. ${ }^{38}$ Thus, an adequate adherence might be essential for further CPAP trials in stroke survivors.

There was only 1 RCT with a long-term follow-up over 5 years, which showed a longer cardiovascular event-free survival with CPAP. ${ }^{34}$ This matches the findings of the largest available observational study in this field, which also found a reduction of cardiovascular events in stroke patients treated with CPAP. ${ }^{39}$ Considering data from the general population, a beneficial influence of CPAP on vascular prognosis could also be expected in patients with neurologic sequelae. ${ }^{9,11,12}$ However, the available data are not sufficient to confirm this hypothesis.

The overall significant positive result on the neurofunctional outcome (figure 4) has to be interpreted with caution because of several limitations. The analysis and comparability of the included studies are limited by the high dropout rates and small sample sizes, as well as a relevant heterogeneity across the RCTs due to methodologic differences (partial blinding, onset of treatment, follow-up duration, and outcome parameters) and, to a lesser, extended clinical diversity (inclusion of AHI, TIA vs stroke). We tried to account for this by using random-effects models for our analyses, and because of the available heterogeneous datasets, we used both NIHSS and CNS changes to increase the sample size for the assessment of the neurologic outcome and contacted authors for individual patient data. Because there is no defined minimal, clinically important difference regarding the improvement in NIHSS and CNS, a more appropriate outcome assessment would have included the analysis of independency scales such as the Barthel Index. A meta-analysis of these scales could not be performed because of insufficient data.

The data on CPAP treatment after stoke are promising. However, because of the heterogeneity and limitations of the currently available trials, the data are not sufficient to draw confident evidence-based conclusions about the beneficial effects on neurologic and cognitive outcomes or long-term survival. Apart from clinical scales and neurocognitive testing, further trials with well-predefined outcome parameters should also focus on imaging methods and include a larger number of patients. Further RCTs are required to clarify the place of CPAP in the treatment of SDB after stroke.

\section{Author contributions}

Anne-Kathrin Brill, Thomas Horvath, and Andrea Seiler: study concept and design, acquisition, analysis, and interpretation of data. Millene Camilo: study concept and design, acquisition of data. Alan G. Haynes: statistical analysis, interpretation of data. Sebastian R. Ott: study concept and design, critical revision of manuscript. Matthias Egger and Claudio L. Bassetti: study concept and design, analysis and interpretation of data, critical revision of manuscript.

\section{Study funding}

Funded by Swiss National Science Foundation grants 320030-149752 and 320030-125069.

\section{Disclosure}

The authors report no disclosures relevant to the manuscript. Go to Neurology.org/N for full disclosures.

Received September 6, 2017. Accepted in final form January 4, 2018.

\section{References}

1. Bassetti CL, Milanova M, Gugger M. Sleep-disordered breathing and acute ischemic stroke: diagnosis, risk factors, treatment, evolution, and long-term clinical outcome. Stroke 2006;37:967-972.

2. Parra O, Arboix A, Bechich S, et al. Time course of sleep-related breathing disorders in first-ever stroke or transient ischemic attack. Am J Respir Crit Care Med 2000;161: 375-380.

3. Peppard PE, Young T, Barnet JH, Palta M, Hagen EW, Hla KM. Increased prevalence of sleep-disordered breathing in adults. Am J Epidemiol 2013;177:1006-1014.

4. Johnson KG, Johnson DC. Frequency of sleep apnea in stroke and TIA patients: a meta-analysis. J Clin Sleep Med 2010;6:131-137.

5. Hermann DM, Bassetti CL. Role of sleep-disordered breathing and sleep-wake disturbances for stroke and stroke recovery. Neurology 2016;87:1407-1416.

6. Yaggi HK, Concato J, Kernan WN, Lichtman JH, Brass LM, Mohsenin V. Obstructive sleep apnea as a risk factor for stroke and death. N Engl J Med 2005;353:2034-2041.

7. Sahlin C, Sandberg O, Gustafson Y, et al. Obstructive sleep apnea is a risk factor for death in patients with stroke: a 10-year follow-up. Arch Intern Med 2008;168: 297-301.

8. Redline S, Yenokyan G, Gottlieb DJ, et al. Obstructive sleep apnea-hypopnea and incident stroke: the Sleep Heart Health Study. Am J Respir Crit Care Med 2010;182: 269-277.

9. Jonas DE, Amick HR, Feltner C, et al. Screening for obstructive sleep apnea in adults: evidence report and systematic review for the US Preventive Services Task Force. JAMA 2017;317:415-433.

10. Doherty LS, Kiely JL, Swan V, McNicholas WT. Long-term effects of nasal continuous positive airway pressure therapy on cardiovascular outcomes in sleep apnea syndrome. Chest 2005; 127:2076-2084.

11. Marin JM, Carrizo SJ, Vicente E, Agusti AG. Long-term cardiovascular outcomes in men with obstructive sleep apnoea-hypopnoea with or without treatment with continuous positive airway pressure: an observational study. Lancet 2005;365:1046-1053.

12. Peker Y, Glantz H, Eulenburg C, Wegscheider K, Herlitz J, Thunstrom E. Effect of positive airway pressure on cardiovascular outcomes in coronary artery disease patients with nonsleepy obstructive sleep apnea: the RICCADSA randomized controlled trial. Am J Respir Crit Care Med 2016;194:613-620.

13. McEvoy RD, Antic NA, Heeley E, et al. CPAP for prevention of cardiovascular events in obstructive sleep apnea. N Engl J Med 2016;375:919-931.

14. Birkbak J, Clark AJ, Rod NH. The effect of sleep disordered breathing on the outcome of stroke and transient ischemic attack: a systematic review. J Clin Sleep Med 2014;10: 103-108.

15. Kernan WN, Ovbiagele B, Black HR, et al. Guidelines for the prevention of stroke in patients with stroke and transient ischemic attack: a guideline for healthcare 
professionals from the American Heart Association/American Stroke Association. Stroke 2014;45:2160-2236.

16. Davis AP, Billings ME, Longstreth WT Jr, Khot SP. Early diagnosis and treatment of obstructive sleep apnea after stroke: are we neglecting a modifiable stroke risk factor? Neurol Clin Pract 2013;3:192-201.

17. Skolarus LE, Lisabeth LD, Morgenstern LB, Burgin W, Brown DL. Sleep apnea risk among Mexican American and non-Hispanic white stroke survivors. Stroke 2012;43: 1143-1145.

18. Liberati A, Altman DG, Tetzlaff J, et al. The PRISMA statement for reporting systematic reviews and meta-analyses of studies that evaluate healthcare interventions: explanation and elaboration. BMJ 2009;339:b2700.

19. Goldstein LB, Bertels C, Davis JN. Interrater reliability of the NIH Stroke Scale. Arch Neurol 1989;46:660-662.

20. Higgins JP, Altman DG, Gotzsche PC, et al. The Cochrane Collaboration's tool for assessing risk of bias in randomised trials. BMJ 2011;343:d5928.

21. Deeks JJ, Higgins JPT, Altman DG. Analysing Data and Undertaking Meta-Analyses: Cochrane Handbook for Systematic Reviews of Interventions.Hoboken, NJ: John Wiley \& Sons, Ltd; 2008:243-296.

22. R Development Core Team. R: A Language and Environment for Statistical Computing. Vienna, Austria: R Foundation for Statistical Computing; 2011.

23. Schwarzer GM. Meta: General Package for Meta-Analysis: R-Package Version 4.8.3-0. 2015. Available at: cran.r-project.org/web/packages/meta/index.html. Accessed January 18, 2017.

24. Aaronson JA, Hofman WF, van Bennekom CA, et al. Effects of continuous positive airway pressure on cognitive and functional outcome of stroke patients with obstructive sleep apnea: a randomized controlled trial. J Clin Sleep Med 2016;12: 533-541.

25. Minnerup J, Ritter MA, Wersching $\mathrm{H}$, et al. Continuous positive airway pressure ventilation for acute ischemic stroke: a randomized feasibility study. Stroke 2012;43: 1137-1139.

26. Ryan CM, Bayley M, Green R, Murray BJ, Bradley TD. Influence of continuous positive airway pressure on outcomes of rehabilitation in stroke patients with obstructive sleep apnea. Stroke 2011;42:1062-1067.

27. Parra O, Sanchez-Armengol A, Bonnin M, et al. Early treatment of obstructive apnoea and stroke outcome: a randomised controlled trial. Eur Respir J 2011;37:1128-1136.
28. Khot SP, Davis AP, Crane DA, et al. Effect of continuous positive airway pressure on stroke rehabilitation: a pilot randomized sham-controlled trial. J Clin Sleep Med 2016; 12:1019-1026.

29. Hsu CY, Vennelle M, Li HY, Engleman HM, Dennis MS, Douglas NJ. Sleepdisordered breathing after stroke: a randomised controlled trial of continuous positive airway pressure. J Neurol Neurosurg Psychiatry 2006;77:1143-1149.

30. Sandberg O, Franklin KA, Bucht G, Eriksson S, Gustafson Y. Nasal continuous positive airway pressure in stroke patients with sleep apnoea: a randomized treatment study. Eur Respir J 2001;18:630-634.

31. Brown DL, Chervin RD, Kalbfleisch JD, et al. Sleep Apnea Treatment After Stroke (SATS) trial: is it feasible? J Stroke Cerebrovasc Dis 2013;22:1216-1224.

32. Bravata DM, Concato J, Fried T, et al. Auto-titrating continuous positive airway pressure for patients with acute transient ischemic attack: a randomized feasibility trial. Stroke 2010;41:1464-1470

33. Bravata DM, Concato J, Fried T, et al. Continuous positive airway pressure: evaluation of a novel therapy for patients with acute ischemic stroke. Sleep 2011;34:1271-1277.

34. Parra O, Sanchez-Armengol A, Capote F, et al. Efficacy of continuous positive airway pressure treatment on 5-year survival in patients with ischaemic stroke and obstructive sleep apnea: a randomized controlled trial. J Sleep Res 2015;24:47-53.

35. Tomfohr LM, Hemmen T, Natarajan L, et al. Continuous positive airway pressure for treatment of obstructive sleep apnea in stroke survivors: what do we really know? Stroke 2012;43:3118-3123.

36. Duss SB, Seiler A, Schmidt MH, et al. The role of sleep in recovery following ischemic stroke: a review of human and animal data. Neurobiol Sleep Circadian Rhythms 2017, 2:94-105.

37. Tsivgoulis G, Alexandrov AV, Katsanos AH, et al. Noninvasive ventilatory correction in patients with acute ischemic stroke: a systematic review and meta-analysis. Stroke 2017;48:2285-2288.

38. Javaheri S, Barbe F, Campos-Rodriguez F, et al. Sleep apnea: types, mechanisms, and clinical cardiovascular consequences. J Am Coll Cardiol 2017;69:841-858.

39. Martinez-Garcia MA, Soler-Cataluna JJ, Ejarque-Martinez L, et al. Continuous positive airway pressure treatment reduces mortality in patients with ischemic stroke and obstructive sleep apnea: a 5-year follow-up study. Am J Respir Crit Care Med 2009; 180:36-41. 


\title{
CPAP as treatment of sleep apnea after stroke
}

\author{
A meta-analysis of randomized trials
}

Anne-Kathrin Brill, MD, Thomas Horvath, MD, Andrea Seiler, MD, Millene Camilo, PhD, Alan G. Haynes, PhD, Sebastian R. Ott, MD, Matthias Egger, MD, and Claudio L. Bassetti, MD

Cite as: Neurology ${ }^{\circledR}$ 2018;90:e1222-e1230. doi:10.1212/WNL.0000000000005262
Correspondence

Prof. Bassetti

claudio.bassetti@insel.ch

\section{Study question}

Do existing randomized controlled trials (RCTs) support the efficacy of continuous positive airway pressure (CPAP) in stroke patients with sleep-disordered breathing (SDB)?

\section{Summary answer}

Existing RCTs indicate that CPAP may aid neurologic recovery in stroke patients with SDB.

\section{What is known and what this paper adds}

Obstructive sleep apnea (OSA), which is a form of SDB and a common comorbidity in stroke patients, can be effectively treated with CPAP in the general population, but studies in stroke patients have yielded conflicting results. This metaanalysis provides evidence supporting the efficacy of CPAP in aiding neurologic recovery in stroke patients with SDB.

\section{Design, size, and duration}

This study began with a systematic search of Medline, Embase, and the Cochrane Library for RCTs published between January 1980 and November 2016 that compared CPAP to either sham CPAP or usual care in patients with SDB and either TIA or stroke. RCT bias was assessed with the Cochrane Risk of Bias Tool.

\section{Participants and setting}

The meta-analysis examined 10 RCTs published between 2001 and 2016 with a total of 564 participants with OSA following either TIA or stroke. In total, the CPAP, sham CPAP, and usual care groups included 300, 37, and 227 participants. The settings included acute care hospitals and rehabilitation units.

\section{Primary outcomes}

The primary outcome was the overall neurofunctional improvement with CPAP as measured with either the NIH Stroke Scale (NIHSS) or the Canadian Stroke Scale.

\section{Main results and the role of chance}

NIHSS or Canadian Stroke Scale data were available for 6 RCTs (166 CPAP group participants; 167 control group

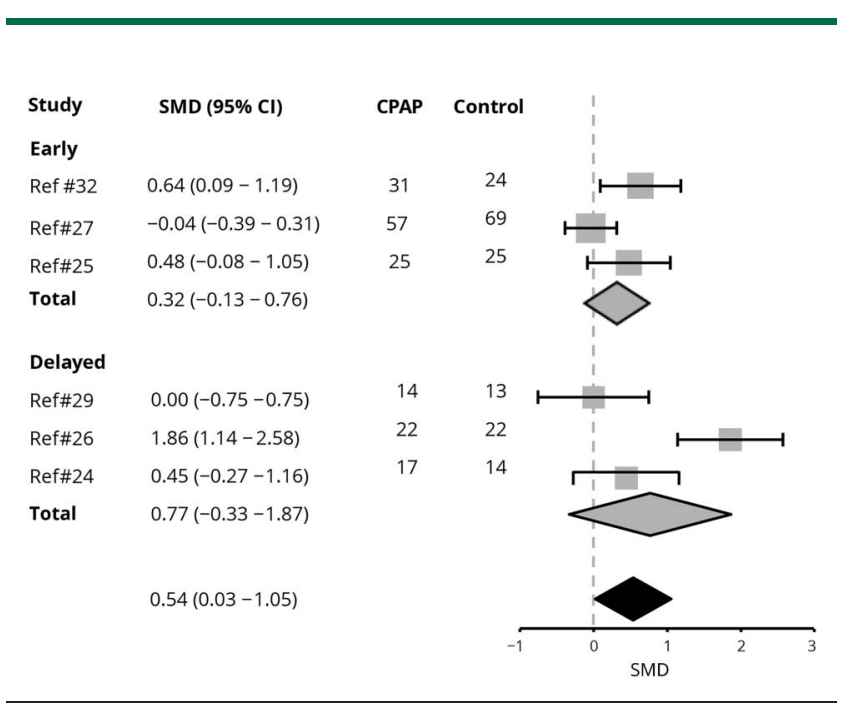

participants). The standardized mean difference for neurofunctional improvement with CPAP was 0.5406 (95\% confidence interval $0.0263-1.0548)$, but the heterogeneity across studies was considerable $\left(I^{2}=78.9 \%\right.$; $\left.p=0.0394\right)$.

\section{Bias, confounding, and other reasons for caution}

The RCTs had high participant withdrawal rates and relatively small sample sizes. Few of the RCTs had matched control groups. Methodologic inconsistencies resulted in high heterogeneity. The minimum clinically important improvements on the NIHSS and Canadian Stroke Scale are undefined.

\section{Generalizability to other populations}

The RCTs might have disproportionately included patients with mild symptoms. This would limit generalizability to patients with severe symptoms.

\section{Study funding/potential competing interests}

This study was funded by the Swiss National Science Foundation. The authors report no competing interests. Go to Neurology.org/ $\mathrm{N}$ for full disclosures.

A draft of the short-form article was written by M. Dalefield, a writer with Editage, a division of Cactus Communications. The authors of the full-length article and the journal editors edited and approved the final version. 


\section{Neurology}

CPAP as treatment of sleep apnea after stroke: A meta-analysis of randomized trials Anne-Kathrin Brill, Thomas Horvath, Andrea Seiler, et al.

Neurology 2018;90;e1222-e1230 Published Online before print March 9, 2018

DOI 10.1212/WNL.0000000000005262

This information is current as of March 9, 2018

\section{Updated Information \&} Services

References

Subspecialty Collections

Permissions \& Licensing

Reprints including high resolution figures, can be found at: http://n.neurology.org/content/90/14/e1222.full

This article cites 36 articles, 16 of which you can access for free at: http://n.neurology.org/content/90/14/e1222.full\#ref-list-1

This article, along with others on similar topics, appears in the following collection(s):

Infarction

http://n.neurology.org/cgi/collection/infarction

Sleep apnea

http://n.neurology.org/cgi/collection/sleep_apnea

Information about reproducing this article in parts (figures,tables) or in its entirety can be found online at:

http://www.neurology.org/about/about_the_journal\#permissions

Information about ordering reprints can be found online:

http://n.neurology.org/subscribers/advertise

Neurology ${ }^{\circledR}$ is the official journal of the American Academy of Neurology. Published continuously since 1951, it is now a weekly with 48 issues per year. Copyright () 2018 American Academy of Neurology. All rights reserved. Print ISSN: 0028-3878. Online ISSN: 1526-632X.

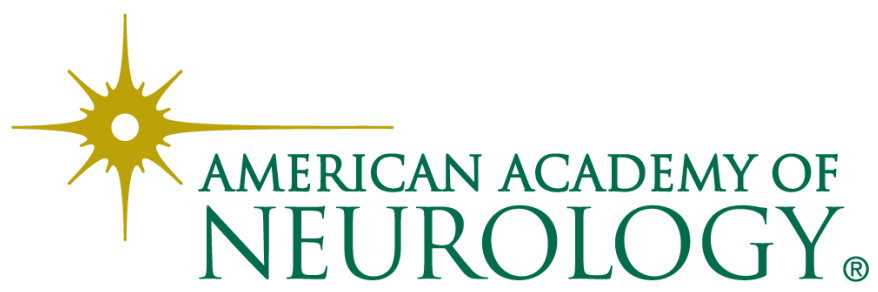

